\title{
Severe transient nephrotic syndrome in diabetic pregnancy
}

The nephrotic syndrome is uncommon in pregnancy, probably complicating fewer than one in 1000 pregnancies.' In the absence of pre-existing clinical renal disease the cause is probably pre-eclampsia in most patients. Diabetic glomerulosclerosis has been noted as a possible cause but no evidence offered about its frequency.' We report a case of severe transient nephrotic syndrome in a pregnant diabetic patient subsequently followed up for over one year.

\section{Case report}

A 29 year old woman with a history of insulin dependent diabetes for 19 years presented at 10 weeks' gestation in her second pregnancy. The previous pregnancy had been normal, with no proteinuria or hypertension. At 11 weeks' gestation her renal function was assessed: there was no proteinuria and creatinine clearance was $78 \mathrm{ml} / \mathrm{min}$. Blood pressure was normal $(120 / 70 \mathrm{~mm} \mathrm{Hg})$ and booking glycosylated haemoglobin value satisfactory $(8 \cdot 4 \%$; non-diabetic range $5 \cdot 5-8 \cdot 5 \%)$. There was no evidence of diabetic retinopathy or neuropathy.
$0 \cdot 1 \%,{ }^{1}$ and more recent observational studies have found incidences of $0.05 \%$ and $0.08 \%{ }^{3}$ Many aetiologies have been observed, including acute and chronic glomerulonephritis and pre-eclampsia.

In our patient the aetiology of the transient nephrotic syndrome was uncertain, as we did not think that renal biopsy was justified before delivery and the patient declined biopsy afterwards. The very acute onset late in pregnancy and rapid resolution after delivery must be explained and these factors together with the normal complement concentrations and antistreptolysin $\mathrm{O}$ titre make acute glomerulonephritis unlikely.

Pre-eclamptic nephropathy would account for the mode of onset and speed of resolution; nevertheless, in the largest series of patients with the nephrotic syndrome due to pre-eclampsia all 13 patients had severe hypertension $(>170 / 110 \mathrm{~mm} \mathrm{Hg})$ and a pronounced rise in the serum urate concentration, neither of which occurred in our patient. ${ }^{4}$ The persistently high creatinine clearance during the nephrotic phase also contrasts with the reduced creatinine clearance $(<100 \mathrm{ml} / \mathrm{min})$ seen in a group of patients with pre-eclamptic nephropathy, ${ }^{2}$ and overall it seems unlikely that pre-

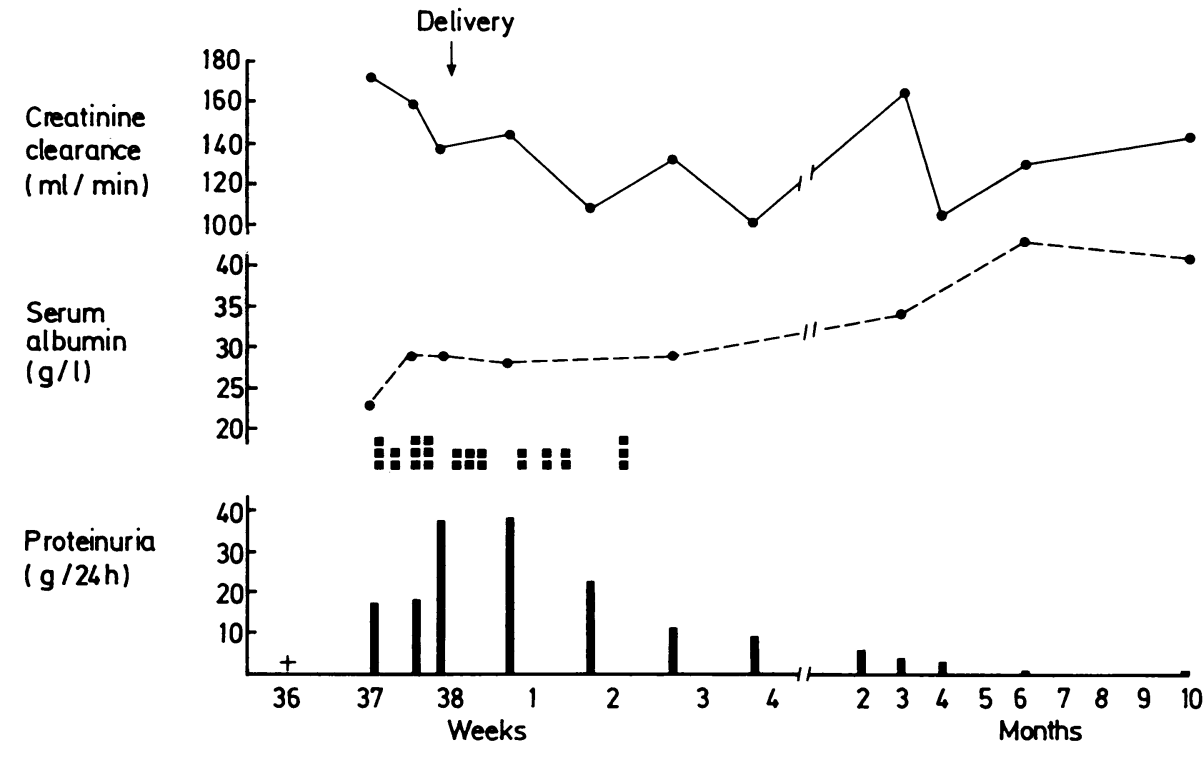

Serum albumin concentrations, creatinine clearance, and 24 hour proteinuria before and after delivery.

- $=20 \mathrm{~g}$ albumin concentrate given intravenously.

Diabetes was managed with twice daily injections of highly purified porcine insulins (Velosulin and Insulatard; Nordisk, Gentofte), and regular home blood glucose monitoring was undertaken (Reflomat; Boehringer Mannheim)

Pregnancy proceeded uneventfully for the next six months, the patient attending the combined antenatal and diabetic clinic fortnightly and achieving good diabetic control. At 34 weeks routine urine analysis showed no proteinuria. Two weeks later Albustix testing disclosed $1+$ proteinuria; blood pressure was $120 / 70 \mathrm{~mm} \mathrm{Hg}$ and the glycosylated haemoglobin value $7 \cdot 9 \%$. After a further week (37 weeks' gestation) she had pronounced peripheral oedema and 4+ proteinuria; blood pressure was $130 / 90 \mathrm{~mm} \mathrm{Hg}$ and serum albumin concentration $23 \mathrm{~g} / \mathrm{l}$. Urinary protein excretion of $16.3 \mathrm{~g} / 24 \mathrm{~h}$ and creatinine clearance of 171 $\mathrm{ml} / \mathrm{min}$ were recorded (figure). Albumin $220 \mathrm{~g}$ was given by intravenous infusion over the next four days, the serum albumin concentration rising to $29 \mathrm{~g} / \mathrm{l}$ but proteinuria increasing to $37.0 \mathrm{~g} / 24 \mathrm{~h}$. Blood pressure was mildly raised, never higher than 135/90 mm Hg. Platelet count, serum urate concentration, serum complement values, and the antistreptolysin $\mathrm{O}$ titre were all normal. Electrophoresis of the urinary protein suggested glomerular leakage with no evidence of protein selectivity.

Prompt elective delivery was planned but at 38 weeks the patient went into labour spontaneously and delivered a healthy boy weighing $2710 \mathrm{~g}$. The placenta was normal macroscopically and on microscopical examination and the baby had no complications in the neonatal period. The mother was managed by administration of oral frusemide and intravenous albumin concentrate (figure). Proteinuria declined rapidly, the creatinine clearance remaining static. Blood pressure was slightly raised four days after delivery $(150 / 100 \mathrm{~mm} \mathrm{Hg})$ and was controlled with metoprolol $50 \mathrm{mg}$ daily; the drug was stopped after three weeks and blood pressure was normal thereafter. Three months after delivery proteinuria was $4 \cdot 0$ $\mathrm{g} / 24 \mathrm{~h}$, creatinine clearance $165 \mathrm{ml} / \mathrm{min}$, and the serum albumin concentration $34 \mathrm{~g} / \mathrm{l}$. Sixteen months after delivery proteinuria had dropped to $0.58 \mathrm{~g} / 24 \mathrm{~h}$ with creatinine clearance $106 \mathrm{ml} / \mathrm{min}$.

\section{Comment}

A true incidence for the development of the nephrotic syndrome in pregnancy is difficult to assess. Standard textbooks quote figures of less than eclampsia would explain the nephrotic syndrome in our patient. Schreiner suggested that hypersensitivity to products of conception may produce the "nephrotic syndrome of pregnancy," probably by an effect on glomerular basement membrane charge, ${ }^{1}$ while other workers have proposed a simple mechanical effect of the gravid uterus compressing the inferior vena cava and producing renal vein thrombosis. ${ }^{3}$

Transient nephrotic syndrome complicating a diabetic pregnancy has no previously been reported. While the mechanisms outlined above may be implicated, it may also be that the combined stimuli to renal hyperfiltration of diabetes and pregnancy produce transient glomerular damage, especially in kidneys already damaged subclinically by prolonged diabetes. Whatever the mechanism, the successful outcome of the pregnancy in our patient and the good renal function persisting beyond one year of follow up show that severe nephrotic syndrome late in diabetic pregnancy does not necessarily herald a rapid decline in maternal renal function.

1 Schreiner GE. The nephrotic syndrome-nephrosis of pregnancy. In: Strauss MB, Welt LG, eds. Diseases of the kidney. Boston: Little Brown and Co, 1963:389-93.

2 Weisman SA, Simon NM, Herdson PB, Franklin WA. Nephrotic syndrome in pregnancyclinical, histological and fine structural studies. Am f Obstet Gynecol 1973;117:867-83.

Wallace MR, Smedley MG. The transient nephrotic syndrome of pregnancy. NZ Med $\mathcal{J}$ 1970;71:208-12.

4 First MR, Ooi BS, Jao W, Pollak VE. Pre-eclampsia with the nephrotic syndrome. Kidney Int 1978;13:166-77.

(Accepted 7 August 1985)

Diabetic Unit, Royal Infirmary and Royal Maternity Hospital, Glasgow

KENNETH R PATERSON, MB, MRCP, senior registrar in medicine C BURNETT LUNAN, MD, FRCOG, consultant obstetrician ANGUS C MACCUISH, MD, FRCP, consultant physician

Correspondence to: Dr K R Paterson, General Medicine Wards 4/5, Royal Infirmary, Glasgow G4 OSF. 